\title{
Mercado da/de carnes: corpos imprevistos na biopolítica ${ }^{\star}$
}

\author{
Michele de Freitas Faria de Vasconcelos, ${ }^{I, \star \star}$ Luiz Felipe Zago ${ }^{I I}$ \\ ${ }^{I}$ Universidade Federal de Sergipe, São Cristóvão, SE, Brasil

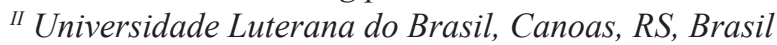

\section{Resumo}

A fim de pensar sobre regimes de visibilidades e de verdades corporais no terreno da biopolítica de face neoliberal, o artigo articula conceitualmente discussões realizadas em dois campos distintos de pesquisa: o Manhunt, um site de relacionamentos direcionado para homens gays na internet, e um Centro de Atenção Psicossocial para Álcool e outras Drogas (CAPS-ad). Embora tratando-se de duas pesquisas realizadas em campos radicalmente diferentes, a categoria "Mercado da/de Carnes" emergiu como articuladora das análises, possibilitando a aproximação empírica e teórica sobre a produção de arranjos corporais focando em performatividades de masculinidade no território de um CAPS e em um site de relacionamento. Baseado em descrições etnográficas do CAPS e do site Manhunt, bem como em entrevistas semi-estruturadas com seus respectivos usuários, o presente artigo constrói a intersecção teórica e política das normas de gênero na contemporaneidade, apontando (re)existências corporais possíveis no mercado biopolitico para os sujeitos participantes das pesquisas.

Palavras-chave: biopolitica; corpo; gênero; governamentalidade; masculinidades.

\section{Market of flesh: unpredictable bodies in biopolitcs}

\section{Abstract}

The article seeks to reflect upon regimes of visibilities and corporeal truths in the field of neoliberal biopolitics. It articulates conceptual discussions undertaken in two distinct research fields: one is the online gay cruising site, Manhunt, and the other is a Center of Psychosocial Attention for Alcohol and other Drugs (CAPS-ad). Although these two researches have been undertaken in radically different fields, the category of "Market of Flesh" emerged as an analytical articulator, promoting empirical and theoretical approach on the production of bodily arrangements focusing on performativities of masculinities in the territory of CAPS and on the online gay cruising site. Drawing on ethnographic descriptions of the CAPS and the online gay cruising site, as well as on semi-structured interviews with their users, this article builds a theoretical and political intersection of gender norms in contemporary era, pointing out possible corporeal (re)existences in the biopolitics market for the research participants.

Keywords: biopolitics; body; gender; governamentality; masculinities.

\section{Um mercado de duas (ou mais) carnes}

A vontade de escrever este artigo se fez de uma coincidência: ${ }^{*} \mathrm{~s}^{1}$ autor*s desenvolveram duas pesquisas bastante diferentes, que resultaram em duas teses de doutorado que abordaram o conceito de gênero. Além do conceito em comum, os textos das teses partilhavam de um capítulo com títulos bastante similares. Em uma o título era "Mercado da Carne"; noutra, "O Mercado de Carnes". Mas de que(ais) mercado(s) se tratava(m)? Que carnes se encontravam nele(s) expostas?

Uma das pesquisas teve como campo um site de relacionamentos direcionado para homens gays na internet: o Manhunt (ONLINE BUDDIES, c2001) A outra, um Centro de Atenção Psicossocial para Álcool e outras Drogas (CAPS ad) voltado para o cuidado em saúde mental a pessoas que fazem uso abusivo e prejudicial de álcool e outras drogas - CAPS este em que a maioria d*s usuári*s frequentadores compõe a categoria homens. Ambas as pesquisas pretenderam estudar a produção de arranjos corporais, cada uma em seu campo, focando em perfor-

^Agência de financiamento: Coordenação de Aperfeiçoamento de Pessoal de Nível Superior.

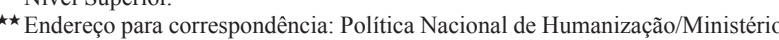
da Saúde. SAF Sul, Trecho 2, Bloco F, Sala 102 Edifício Premiun, Torre II. Setor de Autarquias Sul. Brasília, DF - Brasil. CEP: 90046900 . E-mail: michelevasconcelos@hotmail.com,professorluizfelipezago@gmail.com

Neste texto, utilizou-se asterisco $\left(^{*}\right)$ em lugar de o/a, no sentido de ir de encontro a uma linguagem que tende a universalizar o masculino sem, contudo, manter-se fazendo uso da dicotomia masculino/feminino, por meio da qua também se tende a fixar e essencializar maneiras de fazer gênero em apenas duas extremidades. mances de masculinidade. Nossos campos de pesquisa, muito embora radicalmente distintos, parecem se configurar como dois modos de operar de um mesmo mercado. Na primeira parte desta argumentação, tentamos construir possibilidades analíticas no entremeio desses dois campos, isto é, teceremos considerações conceituais em relação a um mercado que atravessa e constitui os dois campos das pesquisas: aquele que se gesta em tempos de capitalismo financeiro, entre o controle do Estado e do Mercado. Na segunda parte, exploraremos a seguinte pergunta: as nossas pesquisas tratam das mesmas carnes?

Assim, o objetivo desta escrita emerge: discutir o aparecimento de novos corpos masculinos no mercado da biopolítica de face neoliberal, na qual a governabilidade dos corpos e das condutas humanas reside em sua aptidão para o mercado. No momento em que a arte econômica passa a funcionar como critério de razoabilidade das condutas (FOUCAULT, 2008a, 2008b; FARHI NETO, 2010), os corpos incluídos na categoria humana devem regrar e submeter suas condutas ao princípio do empreendedorismo de si - e, assim, corpos figuram como capital humano, raz(ç)ão do mercado financeiro.

Concomitantemente, a biopolítica neoliberal atua sobre os corpos circunscrevendo as normas como limites dentro dos quais, e em relação aos quais, a categoria humana será a eles conferida: as regulações da carne atuam na produção constante de mecanismos de inclusão-exclusão dos corpos, produzindo sujeitos e seus corpos 
literalmente pela encarnação de tais regulações. Isto é, seguimos o insight de Judith Butler (2004, p. 41, tradução nossa) quando a autora sugere que "a norma opera dentro de práticas sociais como o padrão implícito de normalização" e que, muito embora a norma em si possa ser separada analiticamente das práticas dela derivadas, ela ainda resiste à descontextualização. Butler (2004, p. 41 , tradução nossa), então, pontua que "quando [as normas] operam como o princípio normalizante na prática social, elas usualmente permanecem implícitas, difíceis de serem lidas, discerníveis mais clara e dramaticamente pelos efeitos que produzem". Partindo daí, propomos que as regulações da carne hoje atuantes na biopolítica neoliberal são discerníveis precisamente pelos corpos por elas produzidos: os corpos encontrados nos dois campos de pesquisa - tanto no site Manhunt quanto no CAPS - são efeitos materiais, concretos, orgânicos e discursivos, dos processos de inclusão-exclusão de práticas sociais normalizadoras e regulatórias. Os corpos que emergem nos dois campos de pesquisa são inteiramente marcados com a história do nosso tempo presente (FOUCAULT, 2001a).

Os sujeitos pesquisados nos campos dos dois estudos parecem se configurar como dois extremos desse mesmo mercado da/de carnes: em um, homens que caçam corpos perfeitos, corpos-que-importam, de outros homens (nos quais as regulações da carne estão satisfeitas); noutro, homens caçados pelo Estado, já que seus corpos imperfeitos, anticorpos (nos quais as regulações da carne fracassam), borram a face imaculada da figura do indivíduo empreendedor de si mesmo engajado na construção do corpo-que-importa. De um lado, pesquisa-se a carne branca, cheirosa, rija, densa e jovem de homens que mantêm perfis no Manhunt, que ali expõem seus corpos por meio de fotografias: carne-produto que, no laissez-faire do mercado, ganha poder de concorrência; carne-que-importa, nua e cintilante, superexposta em imagens de vários ângulos. De outro lado, pesquisa-se a carniça, o detrito, a carne podre de (anti)corpos adictos que falharam no empreendedorismo de si, que expõem seus corpos a práticas assistenciais especialistas, na medida em que necessitam de tutela estatal para voltarem, de algum modo, a participar da racionalidade neoliberal. Duas vias distintas, mas que parecem compor um mesmo corpo: o corpo biopolítico, em sua face que-importa e em sua podridão. Duas vias monstruosas, na medida em que também comportam forças de experimentação que, tensionando esses corpos sujeitados a estratégias biopolíticas, os vergam, multiplicam seus sentidos e suas possibilidades de feitura, forçando (re)existências corporais. Ao descrever dois campos de pesquisa diferentes, buscamos alinhavar análises que enfoquem os corpos, conforme assinala Vasconcelos (2013), como superfície onde se dão disputas entre formas de sujeição e forças de experimentação na paisagem biopolítica deste início de século XXI.

Foucault (2008a, 2008b) analisa as relações de poder como relações de governo, entendendo governo de modo amplo, como a arte de conduzir as condutas humanas.
Nessa direção, ele desenvolve a noção de governamentalidade para estudar o problema do governo de uns/umas pelos/as outros/as.

De acordo com Farhi Neto (2010), o uso mais amplo e atual da noção de biopolítica dá-se justamente no cenário neoliberal, em que a governamentalidade é traduzida como uma "forma bem específica, embora muito complexa de poder que tem por alvo principal a população, por principal forma a economia política e por instrumento técnico essencial os dispositivos de segurança" (FOUCAULT, 2008a, p. 143). A biopolítica é entendida aqui como "governo da população pelo Estado, mediante a vigilância, o controle e a manipulação de algumas variáveis econômicas; a biopolítica é o governo econômico, que concebe e opera a população a partir de sua economicidade natural" (FARHI NETO, 2010, p. 183). Nesse contexto, "o Estado entrega ao mercado, ou pelo menos divide com ele, a gestão dos aspectos biológicos da população - entre outros, a saúde e o patrimônio genético" (FARHI NETO, 2010, p. 183).

Nesse cenário, a produção da vida e dos corpos humanos é a materialização de um desejo político de empreender a gestão das carnes, materialidades que precisam tomar certo e reto rosto. Dessa forma, "deveríamos falar de 'biopolítica' para designar o que faz com que a vida e seus mecanismos entrem no domínio de cálculos explícitos, e faz do poder-saber um agente de transformação da vida humana" (FOUCAULT, 2001b, p. 134). A biopolítica pode também ser entendida como um conjunto heterogêneo de "tecnologias políticas que, a partir de então, vão investir sobre o corpo, sobre a saúde, as maneiras de se alimentar e de morar, as condições de vida, todo o espaço da existência" (FOUCAULT, 2001b, p. 131). Na "gestão calculista da vida" (FOUCAULT, 2001b, p. 131), o corpo surge como a carne regulada, uma realidade a ser administrada; e quando falamos do corpo, falamos tanto do corpo individual - esse que é meu corpo, diferente do seu corpo - como também falamos do corpo da população, ou do corpo social: a população é um só corpo com mil cabeças (um só corpo de várias carnes). Corpo individual e social são, pois, produzidos e administrados pela biopolítica, a qual se utiliza, para isso, de técnicas disciplinares, que visam docilizar os corpos individuais, e técnicas de regulação populacional, que focam na gestão da vida das massas, da vida da espécie humana.

A apropriação e normalização da vida, dos corpos e das subjetividades pelo biopoder se dá exatamente numa tentativa de penetrar, sujeitar e controlar do mais global ao mais fino grão da vida humana. Para isso, ele atua cada vez mais ampliando seus territórios de intervenção: geográficos, sociais, culturais, simbólicos, existenciais, planetário. Estamos, pois, falando de "um controle que se estende pelas profundezas da consciência e dos corpos da população - e ao mesmo tempo através da totalidade das relações sociais" (HARDT; NEGRI, 2006, p. 43-44). De um governo da "mobilização total" (PELBART, 2009), em que se dá a passagem da ênfase na fabricação de corpos dóceis para o foco na fabricação de cérebros flexíveis e articulados, os quais, por sua vez, comandam corpos 
também maleáveis. De uma tecnologia de poder que em vez de muros, forja-se num campo não territorial atravessado por práticas de sujeição. Um campo móvel, elástico, que opera a céu aberto; um espaço de "diferenças uniformizáveis" (PASSETTI, 2009), um campo de convivência "no confinamento não mais de espaço produtivo, mas de vida” (PASSETTI, 2003, p. 45).

Nessa direção,

o novíssimo biopoder não atua mais apenas segundo o eixo dos exageros do poder soberano estatal em sua ânsia de governamentalidade - a qual, por certo, nem por isso desapareceu, apenas se transformou -, mas atua segundo o eixo flexível do mercado (DUARTE, 2009, p. 45).

Em outros termos, aqui o exercício do poder já não se encontra mais exclusivamente na dependência das ações do poder estatal soberano que faz viver e deixa morrer certas parcelas da população. Para a biopolítica, em sua face neoliberal, o que importa, acima de tudo, é governar para o mercado (FOUCAULT, 2008b).

\section{A carne livre é a carne regulada}

A liberdade de mercado como princípio organizador e regulador do Estado instaura um Estado sob a vigilância do mercado e uma economia de mercado como modelo para o Estado. A racionalidade da governamentalidade de caráter (neo)liberal é marcada pela desconfiança e pela exigência de justificação legal da legitimidade do governo estatal. Dessa forma, é sempre em nome da segurança da sociedade civil, correlato necessário ao Estado, que se coloca a relevância de novas tecnologias de governo da população. De acordo com Foucault (2008a, p. 14), o acionamento do dispositivo da segurança "é uma certa maneira de acrescentar, de fazer funcionar, além dos mecanismos propriamente de segurança, as velhas estruturas da lei e da disciplina". Foucault (2008a, p. 61) continua:

Em outras palavras, a lei proíbe, a disciplina prescreve e a segurança, sem proibir nem prescrever, mas dando-se evidentemente alguns instrumentos de proibição e prescrição, tem essencialmente por função responder a uma realidade de maneira que essa resposta anule essa realidade a que ela responde - anule, ou limite, ou freie, ou regule. Essa regulação no elemento da realidade é que é, creio eu, fundamental nos dispositivos da segurança.

No contexto de operação de dispositivos de segurança, a liberdade é transformada em técnica de governo, elemento indispensável à própria governamentalidade. A liberdade figura justamente como correlato da implantação dos mesmos: "A ideia de um governo dos homens [...], de um poder que se pensa como regulação, só pode se efetuar através de e apoiando-se na liberdade de cada um" (FOUCAULT, 2008a, p. 63-64). Em outras palavras: "o problema dos que governam não deve ser absolutamente saber como eles podem dizer não, até onde podem dizer não, com que legitimidade eles podem dizer não; o problema é saber como dizer sim ao desejo", como regulá-lo (FOUCAULT, 2008a, p. 96).

Fractal, Rev. Psicol., v. 27 - n. 3, p. 219-227, 2015
A palavra liberalismo advém justamente da função que a liberdade vem desempenhar nessa nova arte de governar. Segundo Foucault (2008b, p. 86), a prática governamental desenhada é "gestora da liberdade", ou seja, consome liberdade: "é obrigada a produzi-la, é obrigada a organizá-la”. Uma vez que a governamentalidade (neo) liberal intervém a fim de maximizar a competição, a produção de liberdade relaciona-se com o imperativo de que todos entrem no jogo econômico. Desse modo, “o liberalismo não é o que aceita a liberdade, [...] é o que se propõe a fabricá-la a cada instante" (FOUCAULT, 2008b, p. 88). Nessa direção, no seio dessa prática governamental, institui-se uma relação problemática, sempre móvel, "entre produção de liberdade e aquilo que, produzindo-a, pode vir a limitá-la e a destruí-la" (FOUCAULT, 2008b, p. 87). É nesse sentido que se dá a correlação entre liberdade e segurança: em vez de regulamentar, será preciso gerir.

O (neo)liberalismo será, então, uma arte de governar centrada na gestão calculada dos riscos: ao lado da incitação a viver perigosamente, estabelecem-se múltiplos mecanismos de segurança; ao lado da liberdade, a segurança. Desse modo, a sensação de perigo e de insegurança é condição de possibilidade da governamentalidade (neo)liberal, com vistas a manutenção da soberania de um poder estatal que, para se legitimar, permite a desordem. Em outros termos, permite-se a desordem para administrá-la, expõe-se a vida ao perigo e à insegurança a fim de melhor regulá-la (CANDIOTTO, 2011). O perigo parece aqui funcionar como árbitro entre a liberdade e a segurança dos indivíduos e da coletividade.

Por meio da inscrição do corpo numa moral do esforço (SANT'ANNA, 2009) ou na "pastoral do suor" (COURTINE, 2005[1995], p. 92), acredita-se, então, ser possível desvencilhar-se dos males corporais contemporâneos: obesidade, envelhecimento precoce, câncer etc. Tal moral indica um caminho seguro e sem fim em direção ao corpo e à saúde perfeitos como resultado de um estilo de vida ativo e de uma ocupação sadia do tempo livre. Na corrida pelo corpo são, vendem-se pacotes de prazeres comedidos e regrados, um mundo de prazeres não regulamentados passa a ser vigiado, dando lugar ao lazer e a uma pedagogia do bem-estar (SANT'ANNA, 2009).

Em nome do bem-estar da população, pedagogias (se) inscrevem (n)a carne dos indivíduos como uma espécie de antídoto aos perigos, preservando os contornos de um corpo sempre ameaçado que, ao despir-se de sua organização e regramento, pode se tornar vida infame (FOUCAULT, 2006), corpo abjeto (BUTLER, 2012[1993]; LOURO, 2004), vida-corpo indigno de ser vivido, que não existe senão para apontar o limite para a zona de habitação humana. Eis que o corpo se torna corpo-currículo (ZAGO, 2013a, p. 11): “a carne é 'grade' de conhecimentos pertinentes sobre os indivíduos - ou a 'grade' que encarcera as subjetividades". A cruzada dos empreendedores de si é a da modelação diária de seus corpos, esculpindo e limpando sua carne de todos os vícios, uma vez que a superfície superexposta dos corpos, cada vez mais desnudos, torna-se o modo de legitimar o sucesso de seu empreededorismo. De acordo com Ortega (2005, p. 156), 
o "resultado é a constituição de um indivíduo responsável que orienta suas escolhas comportamentais e estilos de vida para a procura da saúde e do corpo perfeito e o afastamento dos riscos", o qual tem na exposição corporal e na atividade de autoperitagem "a fonte básica de sua identidade" (ORTEGA, 2008, p. 32) - e aí, segundo o autor, emergem as bioidentidades e as biossociabilidades.

Nesse panorama, o discurso do risco desponta como elemento estruturante de bioidentidades e biossociabilidades: "não se trata de assegurar aos indivíduos uma cobertura social dos riscos, mas de conceder a cada um uma espécie de espaço econômico dentro do qual podem assumir e enfrentar os riscos" (FOUCAULT, 2008b, p. 197-198). O indivíduo deve proteger-se dos riscos, administrar como melhor entender sua cobertura de riscos. Subjetivadas por esse discurso, constituem-se as bioidentidades de indivíduos responsáveis e autônomos, portadores de corpos ativos e vigorosos que gozam de um bem-estar pleno e vivem uma vida ativa.

Em outros termos, por meio dessa polícia da vida, as condutas humanas são regradas por uma moral corporal que vai acentuar a vida ativa e contrapor-se à moleza, à flacidez (física e moral), à preguiça, à falta de vigor e de vitalidade. Uma moral que se faz jurisdição, tal como figuram proibições legais e morais acerca do fumo, do uso de certos alimentos e bebidas, até mesmo de certas maneiras de se comportar. Uma moral que é expressão de dispositivos de identificação modelizantes - tais como o educacional, o biomédico, o esportivo, o midiático. Uma subjetividade individualizada e exteriorizada é forjada: “deverás ter um corpo para mostrar!" (AGAMBEN, 2002, p. 130) e, assim, terás sua liberdade individual garantida. Mostre-me seu corpo e serás livre. E assim cada corpo é compelido à ordem, à saúde, à democracia, à exposição.

Se pensarmos que o corpo é instrumento e efeito do biopoder, ou seja, "um instrumento para atingir modelos identitários que nada diferem de imposições sociais difundidas pelos mais diversos meios de convencimento: da educação à mídia" (MISKOLCI, 2006, p. 682), podemos igualmente pensar no corpo - o meu, o seu, os del*s, os nossos corpos - como sendo instrumento e veículo de uma nova rede de relações de poder do tempo presente. Tempo em que o corpo já não é mais apenas docilizado e disciplinado, como o fora outrora. Tempo em que a extração da produtividade corporal é feita por sua (super) estimulação, ou seja, em que o controle-repressão dá passagem ao "controle-estimulação" (FOUCAULT, 2001a), um modo de funcionamento do poder sensivelmente diferente daqueles das disciplinas (embora delas não prescinda), muito mais insidioso e contínuo, menos negativo, pois não proíbe diretamente, funcionamento este que parece solicitar exposições corporais.

\section{Duas carnes no mercado biopolítico}

Na contemporaneidade do biopoder, o corpo permanece alvo e veículo privilegiado de sua atuação. Trata-se de colocá-lo em circulação em um mercado da carne, uma carne específica, uma carne que-importa, uma carne competitiva e distinta do mercado de carnes (múltiplas, inclassificáveis, inomináveis, incapazes de serem identificadas como um corpo organizado).

Carnes que-importam são carnes que atenderam à convocatória de participação no mercado do capital, são carnes que precisam reiteradamente se fazer corpo esquadrinhado, organizado, produzido por técnicas de (bio) poder, pois supostamente é preciso ter um corpo-capital para mostrar. São carnes que necessitam exibir-se em corpos. E assim o fazem os usuários do site Manhunt: ${ }^{2}$ eles criam perfis para expor/descrever a si mesmos e o tipo de relacionamento e de corpo que procuram, publicando, para isso, imagens de seus corpos. Para pensar o funcionamento do mercado da carne do Manhunt, sugerimos analisar brevemente imagens e palavras publicadas nas diferentes capas do site. Cada novo acesso ao endereço do site exibe uma nova capa, nas quais se leem diferentes textos e se veem diferentes imagens. As imagens de capa do Manhunt, apresentadas a seguir, convocam os homens a habitarem o site e podem ser entendidas como peças publicitárias que pretendem divulgar os serviços do site de relacionamento e arregimentar usuários.

Por isso, as capas do Manhunt parecem funcionar como um mostruário de carnes que almeja exibir aquilo que está supostamente disponível dentro do site, prometendo uma correspondência entre aquilo (e aqueles) que está posto nas capas com os corpos dos milhares de usuários cadastrados. Como que para anunciar e vender um produto, é possível sugerir, ainda, que as capas do Manhunt articulam imagem e texto em uma estratégia de fishing, que visa a fisgar os indivíduos a participarem do site - mas não quaisquer indivíduos: o Manhunt, como o próprio nome diz ("caça aos homens" ou "caça de homens", em inglês), oferece um conjunto de possibilidades técnicas através das quais homens podem fisgar outros homens através de seus perfis online. Isto é: os corpos caçadores e os corpos caçados são corpos de homem. Mas ali não se exibem e não se caçam quaisquer corpos; então, que corpos de homens são autorizados a ali se exibirem? Que corpos ali são caçados?

Nas imagens de capa mostradas abaixo, vemos algumas poses, alguns olhares e alguns modos de exibir corpos de homens que reaparecem nas fotografias dos perfis online dos usuários e que podem nos ajudar a pensar com a pergunta acima.
${ }^{2}$ Foi dentro do Manhunt onde realizamos uma etnografia virtual entre março de 2009 e fevereiro de 2012. Para tanto, criamos um perfil online no Manhunt, no qual um de nós apresentava-se como pesquisador e convidava os demais usuários do site para participarem de entrevistas. Durante as observações etnográficas, pudemos arquivar perfis (com textos escritos e imagens de corpos) e produzir entrevistas com homens gays usuários do site de relacionamento. 
Figura 1 - Conjunto de imagens de capa do Manhunt
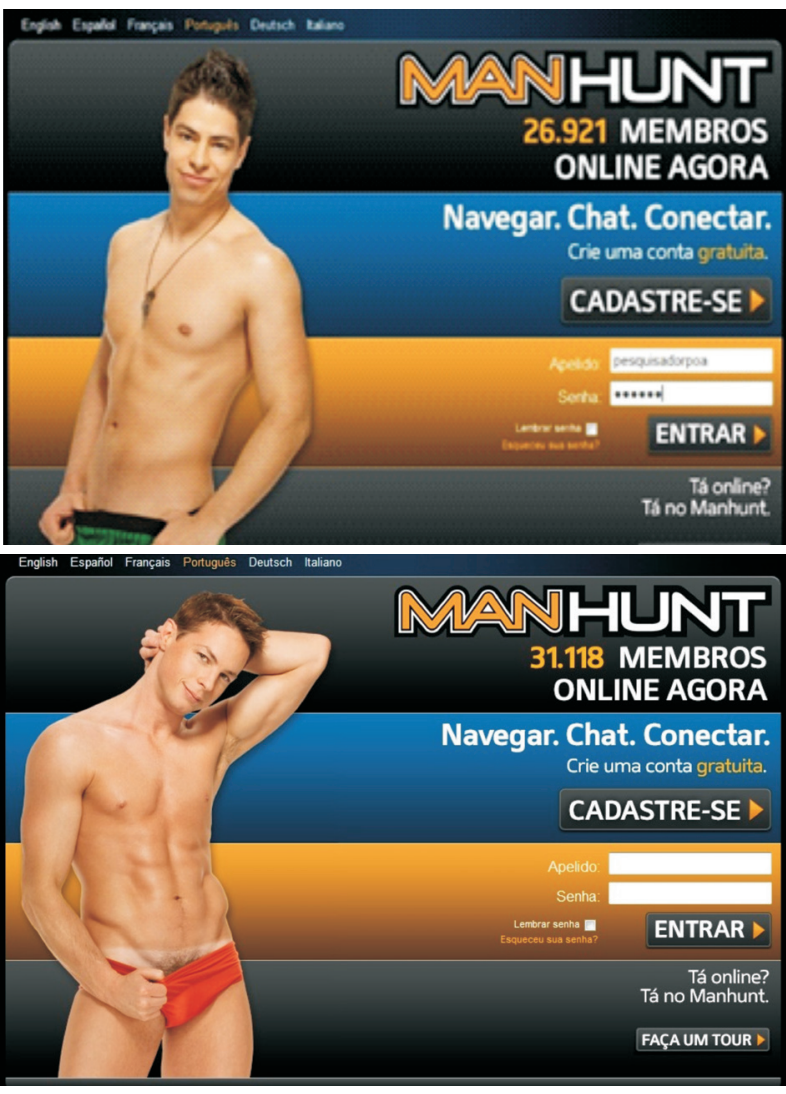

Fonte: site Manhunt.

Nas imagens de capa do Manhunt, há rastros dos modos de exibição dos corpos dos usuários do Manhunt que nos servem para mencionar e reconstruir modos como os usuários fazem aparecer seus corpos em seus perfis online. Mais que isso, as capas do Manhunt, além de exibir e mostrar corpos como produtos através de elementos imagéticos e textuais, também operam no apagamento, silenciamento e obscurecimento de alguns outros corpos que aí não aparecem. Nessas imagens há rastros de alguns corpos, por exemplo, que são empurrados para as bordas do visível, isto é, corpos que são chamados, convocados e impelidos a não se mostrar e a não se exibir.

Entre os textos escritos veiculados nas várias capas do Manhunt, arquivados durante as observações etnográficas virtuais, estão os seguintes: "Encontre-o num piscar de olhos"; "Alto, baixo, ativo, versátil... seu homem está a um clique de distância quando você usa a busca do $M a$ nhunt"; "Quer saber mais? Faça um tour pelo Manhunt"; "Tem alguém pra você". Pensando nessas frases, e sempre lembrando dos corpos exibidos (e exibíveis) que se articulam a elas nas capas do Manhunt, cabe perguntar: quem é capaz de se deixar clicar nos sites que prometem "o seu homem a um clique de distância"? Que corpos são passíveis de exibição online?

Nessas duas figuras, os corpos-modelo aparecem aí polarizados na parte esquerda de ambas as imagens, em frente a faixas em tons de cinza, preto, azul e amarelo. As peles dos corpos-modelo, extensamente visíveis, contrastam com as faixas de cores do fundo da imagem: essas são peles que facilmente classificaríamos como brancas.

Fractal, Rev. Psicol., v. 27 - n. 3, p. 219-227, 2015
As peles dos corpos-modelo parecem homogêneas, e sua homogeneidade só é quebrada justamente pelas cores das cuecas/sungas. Suas peles só são extensamente visíveis porque estão seminus: há pouco dos corpos-modelo a ser coberto nas suas exibições, e mesmo que esse pouco permaneça coberto nas imagens, ainda sim supomos que aquelas partes ali estejam por debaixo dos panos, literalmente. Se há pouco a ser coberto nos corpos-modelo, também há pouco neles a ser descoberto: não é preciso que os pênis sejam exibidos nas imagens, pois parecemos ter a certeza de sua existência nesses corpos de homem.

Nos perfis online do site, alguns homens publicam os seguintes textos: "Tenho $1.83 \mathrm{~m}, 86 \mathrm{~kg}$, sou malhado, 21 cm, HIV - (HIV negativo), enfim, algumas fotos estão aí". Nesse texto, o usuário fornece uma lista escrita de características corporais e as remete para as fotografias publicadas, como que para legitimá-las, em que o texto reforça as imagens e as imagens, o texto. Outro usuário escreve "[sou] Gatão Pauzudo, como na foto, mas não se prenda a isso": aí, ele se refere ao tamanho de seu pênis no texto escrito, cuja imagem está publicada no perfil, também apostando em uma relação de legitimação entre texto e imagem, sugerindo que o leitor/visualizador de seu perfil não se prenda à fotografia do pênis, dando a entender que há mais informações sobre si do que a imagem mostra.

Outro homem escreve: "só tem peito aqui nas minhas fotos, mas se você reparar bem, atrás dele tem um coração, tá?". Aí o usuário alude à parte de seu corpo publicada nas suas imagens (seu peito), mas sugere que há algo que excede essas imagens ou algo que não pode ser apreendido pelas imagens, algo que não passível de exibição ou de visualização através de imagens. Outro usuário escreve: "apesar das fotos bastante ordinárias (porque isso é o que a galera quer ver mesmo!), não curto fast foda", mencionando as fotografias publicadas em seu perfil como sendo "ordinárias" - nelas ele aparece nu com o pênis ereto -, mas as contrapõe dizendo que, apesar das imagens "ordinárias" que sugerem uma disponibilidade exclusiva para prática sexual, ele não curte "sexo rápido", ou "fast foda", o que indica uma relação de oposição entre imagem e texto nesse perfil.

Em outro perfil, lê-se: "QUER QUE EU DIGA + QUE AS FOTOS?", em que o homem lança uma pergunta sobre aquilo que excede as imagens publicadas em seu perfil e, então, passa a listar no texto escrito de seu perfil as especificações sobre traços de sua personalidade e formas com que gosta de praticar sexo, o que indica uma relação de complementaridade entre texto e imagem. Finalmente, um dos homens habitantes do Manhunt escreve: "SEM FOTO, SEM CHANCE!!! SEM FOTO, SEM CHANCE!!! SEM FOTO, SEM CHANCE!!!”, três vezes e em letras maiúsculas, em tom de exclamação, atestando a importância fundante das imagens para a criação de quaisquer vínculos com outros homens. Ora: no mercado da/ de carne, a carne precisa estar exposta e fazer-se visível.

Nessas condições, o corpo é enclausurado por um "totalitarismo fotogênico" que exorta "que tudo no corpo seja preparado para ser visto, exposto, colocado em pose: até mesmo o que é considerado avesso a toda pose 
e a toda exposição começa a ser coagido a aparecer" (SANT'ANNA, 2005, p. 107). Se o corpo exibível e mostrável tem um preço, esse preço não é apenas monetário. Esse preço é, sobretudo, visual. Paga-se, e paga-se um preço alto, para produzir um corpo exibível. Eis o triunfo dos corpos-que-importam: agregar olhares em si, fazer convergir olhares para si, exibir-se para o olhar do(s) outro(s): o indivíduo que constrói pra si um corpo-que-importa "não anda; ele conduz seu corpo exibindo-o como objeto imponente" (COURTINE, 2005[1995], p. 82). A adesão ao projeto de construção do corpo-que-importa, seja pela frequência às academias de ginástica, seja pela ingestão de suplementação alimentar, nunca tem como objetivo fazer o corpo fechar-se em si mesmo ou esconder-se do mundo. Não: o corpo mostrável demanda o(s) outro(s), o olhar do(s) outro(s); o corpo exibível existe em função do e em relação ao olhar do(s) outro(s) - o corpo-que-importa implora para ser visto, seja tirando a camiseta na boate, seja publicando fotografias do corpo no perfil online do Manhunt. O corpo-que-importa quer "[i]mpor-se, pesar no olhar alheio [...]. O músculo marca. Ele é um dos modos privilegiados de visibilidade do corpo no anonimato urbano das fisionomias" (COURTINE, 2005[1995], p. 82-83). O corpo-que-importa emerge e ganha sentido precisamente na relação do olhar do(s) outro(s) sobre ele, pois parece que nenhuma parte dos corpos-que-importam deve, nem pode mais ser escondida.

Nada mais é escondido supostamente. Nosso argumento é que alguns corpos são mostráveis e exibíveis no mercado da/de carnes, como se a exibição fosse seu direito. Outros corpos serão empurrados para a borda do visível, anticorpos expulsos do campo visual no qual se assenta o mercado de/das carnes. Portanto, trata-se de entender o olhar - os modos de olhar, os modos de ser olhado, os modos de não-olhar ou de não-se-dar-ao-olhar - como um aspecto fundante da experiência do corpo no mercado biopolítico.

Dessa forma, será preciso supor que as mesmas categorias através das quais vemos e exibimos os corpos são as mesmas que trabalham na tentativa de in-visibilizar outros corpos - os anticorpos, os corpos imperfeitos, que escapam às regulações que con-formam a carne constituindo, assim, um regime de in-visualidade como seu próprio avesso. Se os corpos-modelo das capas do Manhunt são a carne que-importa no mercado da carne, a carne podre dos corpos adictos, a carniça dos corpos que falham, negam ou resistem aos estímulos do empreendedorismo de si e da moral do esforço diário são os anticorpos no mercado de carnes: o avesso da mesma produção biopolítica.

No momento em que a arte econômica e, com ela, a cultura do risco, a cultura da vida ativa e a cultura somática do empreendedorismo de si passam a funcionar como critério de razoabilidade das condutas, produzem-se novas marcações por meio das quais se fabricam, se organizam e se valorizam corpos. E, com isso, constituem-se também novas desqualificações e desvalorizações. Assim, situamos a problemática da segunda pesquisa da qual nos valemos nesta discussão: em nome da preservação da qualidade de vida de uns/umas (ou em nome da preservação ostentatória dos corpos-que-importam), funda-se a impossibilidade da vida de outr*s muit*s que falharam ou resistiram a fazer de seus corpos empresas, produtos exibíveis. Esses corpos também precisam ser caçados, mas de um modo avesso à caça realizada no Manhunt: não se caçam esses corpos para espelhar o si mesmo de corpos engajados no empreendedorismo de si. Ao contrário, são corpos perseguidos na medida em que, incapazes de (auto) policiar suas carnes e organizar seus corpos, parecem indicar o limite do humano. Sob o risco de contaminar a população da qualidade de vida, precisam ser exibidos, identificados como os novos anormais (DUARTE, 2009) a serem identificados-visibilizados, incluídos na norma.

No momento em que vigor do corpo, beleza, juventude, longevidade, saúde como um plus, um superávit de energia e vitalidade funcionam como os novos critérios que avaliam o valor dos indivíduos e grupos, os inábeis a cuidar de si despontam como as novas figuras de anormalidade (DUARTE, 2009): velhos/as, gordos/as, sedentários/as, fumantes, bêbados/as, viciados/as, adictos/ as, compulsivos/as, pessoas que vivem com deficiências, pessoas que vivem com HIV, anoréxicas. A carne humana que não se coloca a serviço do capital financeiro, a carne humana que escapa a esse contínuo "dar forma", essa carne humana é podre, é carniça, precisa ser descartada.

[...] Quando você se entrega num espaço assim, é carne morta. [...] É carne morta que vende em mercado. ${ }^{3}$

[...] Parece que o mercado de carnes continuou, ${ }^{4}$ as pessoas estão expostas aí. Parece que nenhuma carne tá boa para consumo. Nossos invisiveis, aqui são visiveis, mas são visiveis podres.

Incluídos nas políticas sociais e de inclusão (e, nesse caso particular, em serviços assistenciais como o CAPS ad), os invisíveis tendem a ser iluminados, registrados como corpos indignos, visíveis podres, infames, uma vez que sua pele exibe a marca da abjeção, dos excessos, dos desvios, da inabilidade de um cuidar de si que se faz nos registros do que Ortega (2008) intitula de bioascese. No CAPS ad encontram-se sujeitos que falharam ou resistiram ao governo mercadológico dos corpos e que, por isso, parecem assinalar zonas de ingovernabilidade. Nesse sentido, caberia perguntar: por que essa necessidade de visibilidade? Nessa visibilidade residiriam outras funções além do escopo - ele mesmo fundamental para o exercício de poder em questão - de apontar o limite de um possível pré-estruturado para os corpos humanos?

Sob a voga de uma dada democracia representativa, de consenso, parece que, para se obter reconhecimento como sujeito de direitos, é preciso ter um corpo para

\footnotetext{
${ }^{3}$ Fragmento de fala retirado da segunda pesquisa, a qual foi realizada num CAPS ad, autorizada pela Educação Permanente e pela gestão de saúde mental do município em que foi realizada, pactuada junto aos/às atores/atrizes sociais envolvidos/as (usuários/as e profissionais do CAPS em questão e do Projeto de Redução de Danos), para cujos procedimentos metodológicos de realização de grupos focais foram solicitados leitura pública e assinatura de termos de consentimento livres e esclarecidos. Vale dizer que os fragmentos apresentados adiante também foram produzidos do mesmo modo.

${ }^{4} \mathrm{Na}$ segunda pesquisa, o nome do capítulo "O mercado de carnes" foi pensado principalmente porque, na mesma estrutura predial do serviço CAPS ad, funcionava nos anos 80 o antigo mercado de carnes municipal.
} 
mostrar, mesmo que se trate de um corpo a ser reabilitado e mesmo que essa reabilitação nunca venha. A partir dessa exposição corporal, se deverá confessar a indignidade de uma vida que se desviou do caminho seguro prescrito para os/as cidadãos/ãs "de bem” e, que, por isso, precisa ser tutelada pelo Estado, a fim de retomar o caminho rumo à saúde e ao corpo perfeitos. E assim homens que fazem uso abusivo e prejudicial de ad, expõem seus corpos no CAPS com o objetivo de voltarem a ser cidadãos, tal como mostra o fragmento de fala abaixo:

\begin{abstract}
- O CAPS ad me fortaleceu e me reviveu porque eu era um ninguém. Eu era um ninguém e ele me tirou do fundo do poço. [...] e até hoje estou aqui e me sinto homem. [...] eu era um lixo e hoje eu sou um homem porque eu era uma pessoa derrubada. Derrubada, totalmente.
\end{abstract}

- [...] tudo que eu sei, tudo que eu aprendi, através de ser homem, eu aprendi dentro do CAPS. Ser cidadão, correr atrás dos meus direitos.

- [...] no dia a dia dessa conversa com cada um de nós, eles vão ajudando a nós se levantar, a se sentir o mesmo, o cidadão que era antepassado.

- [...] do lixo ao homem, o que vai fazendo sair do lixo? Que características eu preciso para ser isso que vocês chamam de homem?

- Responsabilidade.

- Autoestima, né?

- Força de vontade.

- Vergonha na cara.

- Um homem invejável é aquele que assume suas responsabilidades.

- Anda limpo.

- Pode correr atrás de mulher, mas anda limpo. Não importa que beba, mas tem que se zelar, né?

- E se ele é casado, mantém a responsabilidade com a família.

- [...] trair pode, não é nada demais pular uma cerca... uma vez por ano. Não pode todo dia.

- [...] pode usar drogas cumprindo com seus compromissos. Eu trabalho na minha oficina e uso.

- Ele saber o limite dele, fazer a obrigação primeiro e o que sobrar, ele pode usar droga.

- Desde que mantenha a responsabilidade.

O cidadão participante, o indivíduo crítico, conhecedor de seus direitos e deveres, responsável pelo seu corpo e autovigilante de suas condutas são "avatares que povoam os territórios das pedagogias contemporâneas" (CORAZZA; SILVA, 2003, p. 11), preocupadas em formar indivíduos empresários de si, unidades-empresa que autopoliciam suas condutas e a dos outros, na busca pela qualidade de vida da população da qual fazem parte. A partir dos fragmentos de fala acima destacados, parece que, no CAPS - assim como em outros serviços que compõem as políticas sociais, chamadas políticas de inclusão
- se acionam pedagogias que ensinam uma "cidadania de sujeição", a partir da qual se produz uma "autonomia regulada" (CARVALHO, 2009), em que a garantia de direitos se faz acoplada ao controle das condutas. Em outras palavras, conquista-se a condição cidadã - esta que faz usuários do CAPS ad, por meio das pedagogias ali operadas, voltarem a ser homens de cidadania, ou seja, fazerem parte do gênero humano, serem governáveis, enfim.

A exposição de corpos no Manhunt e a exposição de corpos em um CAPS ad, dois extremos de uma mesma necessidade: (ex)por os corpos a serviço do capital. Mas os corpos - inclusive o próprio corpo do cuidado em ad, diga-se de passagem - sempre se abrem para outras performances que não as prescritas pelas normas regulatórias.

\section{Imprevistos: corpos masculinos}

As duas pesquisas em questão quiseram analisar a feitura de determinados corpos em seus arranjos de masculinidade. Em nosso tempo e na nossa cultura ocidental ainda se articulam, com força de matriz de inteligibilidade, segundo Butler (2012[1993]) os nexos homem-sexo(biológico-anatômico)-gênero-(heteros)sexualidade-paternidade-trabalho-poder de consumo. Por se forjarem colados a essa fôrma-Homem, parece não haver dúvidas de que os corpos-modelos expostos nas imagens de capa do $M a$ nhunt são de homem, pois, embora não se visualizem os pênis daqueles corpos, ainda cremos que estejam suturados à fôrma-Homem. Além disso, se tratam de corpos viris, engajados na cultura somática do faça do seu corpo uma empresa. Parece imperativo convencermo-nos de que aqueles corpos são de homem mesmo sem ver seus pênis, pois aqueles corpos-modelo se gestam colados a uma face hegemônica do gênero masculino, a qual açambarca esses corpos e se impregna em toda sua superfície. Isto é, a montagem dos corpos-modelos do Manhunt se faz articulada a prescrições de um gênero masculino naturalizado: uma performatividade intensa do masculino, nos termos propostos por Butler (2008[1990]).

Vemos e supomos o gênero masculino em todas as partes dos corpos-modelos; depositamos muito peso de verdade em tudo o que vemos nesses corpos e derivamos muitas certezas daquilo que somos capazes de olhar neles. Nesse sentido, no contexto das imagens das capas do Manhunt, menos roupa é mais roupa: embora seminus, aqueles corpos estão convincentemente vestidos com seu gênero masculino. Um gênero masculino que seria perfeito se, em seu processo de feitura, não contivesse um elemento que o faz vacilar: tratam-se, no Manhunt, de homens que buscam se relacionar, afetiva e sexualmente, com outros homens; expõem-se corpos viris de homens que escapam da matriz heterossexual (BUTLER, 2008[1990], 2012[1993]). Esses homens parecem sustentar sua viabilidade no excesso da performatividade do gênero masculino, levando ao exagero a necessidade de exposição corporal no mercado biopolítico.

No CAPS ad, por sua vez, expõem-se os corpos imperfeitos de homens que falharam na feitura de um dito gênero masculino de verdade. No CAPS, como consumidores de políticas públicas, veem uma possibilidade de retorno 
à cidadania da sujeição (CARVALHO, 2009) de corpos podendo, assim, voltarem a ser homens. Nesse espaço, como que não querendo perder alguns ganhos que advêm desse consumo e dessa submissão, muitos homens (nem tão masculinos) fingem, até para si mesmos, querer voltar a ser homem, trabalhador, homem honrado e digno, bom filho, bom marido e bom pai. Esses homens, esses corpos, fingem para adequarem suas condutas a tal performance e, assim, valerem mais ou pelo menos valerem um pouco mais do que nada. O fingimento dos homens usuários do CAPS em querer voltar à hegemonia é uma performatividade do masculino tanto quanto o é nos corpos exibíveis no Manhunt; no entanto, ambas as performatividades produzem rasuras naquilo que supostamente encenam: a fôrma-Homem, perfeita, que nunca é integralmente vivida.

Por entre normas de masculinidades e feminilidades, cujos efeitos são visíveis na superfície mesma dos corpos, as masculinidades que figuram no Manhunt maculam a face masculina hegemônica por engajarem seus corpos em práticas homossexuais - algo que, segundo Zago (2013b), é condição para a intensidade das performatividades do masculino entre usuários de sites de relacionamento gays. Já as masculinidades que habitam o ambiente masculinizado do CAPS ad se tecem como masculinidades infames, pois, de muitos modos, parecem borrar as coordenadas do mapa do gênero masculino. Fragmentos de fala de usuárias, como, por exemplo, "Eu me sinto um traveco no meio deles"; "No começo a gente fica um pouco recolhida [...]. Aí depois é que eles vê a gente como homem, né?" parecem indicar que ali se tecem masculinidades sem homens (BENTO, 2006). Montagens de gênero por hibridações: ousadia de corpos de mulher que figuram no serviço do CAPS ao se apropriarem de elementos masculinizantes; normalizações dos corpos de homens gays que usam o site Manhunt ao se abrigarem na virilidade heterossexual.

Nas performatividades do masculino dos homens usuários do Manhunt e de homens e mulheres usuári*s do CAPS ad expomos as improvisações contínuas da fôrma-Homem-heterossexual que tomam seus corpos e os subjetivam de acordo com as regulações do mercado $\mathrm{da} / \mathrm{de}$ carnes biopolítico. Essas improvisações funcionam como paródias de gênero (BUTLER, 2008[1990]; LOURO, 2004), uma vez que apelam para o exagero e para o fingimento performativos da masculinidade-modelo, normalizante, e, mesmo inadvertidamente, acabam por evidenciar a arbitrariedade dos critérios em relação aos quais se classificam e se distinguem os homens e mulheres verdadeiros/as dos/as falsos/as homens e mulheres.

\section{Referências}

AGAMBEN, G. Homo Sacer: o poder soberano e a vida nua. Belo Horizonte: UFMG, 2002.

BENTO, B. A reinvenção do corpo: sexualidade e gênero na experiência transexual. Rio de Janeiro: Garamond, 2006.

BUTLER, J. Undoing gender. New York: Routledge. 2004.

BUTLER, J. Gender trouble: feminism and the subersion of identity (1990). New York: Routledge, 2008.

BUTLER, J. Cuerpos que importan: sobre los límites materiales y discursivos del "sexo" (1993). Buenos Aires: Paidós, 2012.

CANDIOTTO, C. Cuidado da vida e dispositivo de segurança: a atualidade da biopolítica. In: BRANCO, G. C.; VEIGA-NETO, A. (Org.). Foucault: filosofia \& política. Belo Horizonte: Autêntica, 2011. p. 81-96.

CARVALHO, S. R. Reflexões sobre o tema da cidadania e a pordução de subjetividade no SUS. In: CARVALHO, S. R.; BARROS, M. E.; FERIGATO, S. (Org.). Conexões: saúde coletiva e políticas da subjetividade. São Paulo: Aderaldo \& Rothschild, 2009. p. 23-41.

CORAZZA, S.; SILVA, T. T. (Org.). Manifesto por um pensamento da diferença na educação. In: Belo Horizonte: Autêntica, 2003. p. 9-18. Composições.

COURTINE, J-J. Os Stakhanovistas do Narciso: Body-building e puritanismo ostentatório na cultura americana do corpo (1995). In: SANT'ANNA, D. B. (Org.). Politicas do Corpo: elementos para uma história das práticas corporais. São Paulo: Estação Liberdade. 2005. p. 81-114.

DUARTE, A. Foucault e as novas figuras da biopolítica. In: RAGO, M.; VEIGA-NETO, A. (Org.). Para uma vida nãofascista. Belo Horizonte: Autêntica, 2009. p. 35-50.

FARHI NETO, L. Biopolíticas: as formulações de Foucault. Florianópolis: Cidade Futura, 2010.

FOUCAULT, M. Microfisica do poder. Rio de Janeiro: Graal, 2001a.

FOUCAULT, M. História da sexualidade: a vontade de saber. Rio de Janeiro: Graal, 2001b. v. 1.

FOUCAULT, M. A vida dos homens infames. In: MOTTA, M. (Org.). Estratégia, saber-poder. Rio de Janeiro: Forense Universitária, 2006. Coleção Ditos \& Escritos, v. 4, p. 203-222.

FOUCAULT, M. Segurança, território, população. São Paulo: Martins Fontes, 2008a.

FOUCAULT, M. Nascimento da biopolítica. São Paulo: Martins Fontes, 2008b.

HARDT, M.; NEGRI, A. Império. Rio de Janeiro: Record. 2006.

LOURO, G. L. Um corpo estranho: ensaios sobre sexualidade e teoria queer. Belo Horizonte: Autêntica, 2004.

MISKOLCI, R. Corpos elétricos: do assujeitamento à estética da existência. Revistas de Estudos Feministas, [S.1.], v. 3, n. 13, p. 681-693, 2006.

ONLINE BUDDIES, Inc. Manhunt.net ("Site"). Disponível em: <http://www.manhunt.net/>. c2001. Acesso: 2 abr. 2015. 
ORTEGA, F. Da ascese à bio-ascese - ou do corpo submetido à submissão do corpo. In: RAGO, M.; ORLANDI, L. L.; VEIGANETO, A. (Org.). Imagens de Foucault e Deleuze: ressonâncias nietzscheanas. Rio de Janeiro: DP\&A, 2005. p. 139-173.

ORTEGA, F. O corpo incerto: corporeidade, tecnologias médicas e cultura contemporânea. Rio de Janeiro: Garamond, 2008.

PASSETTI, E. Ecopolítica: procedências e emergência. In: BRANCO, G.; VEIGA-NETO, A. (org.). Foucault: filosofia \& política. Belo Horizonte: Autêntica Editora, 2011. pp. 127-142.

PASSETTI, E. Anarquismos e sociedade de controle. São Paulo: Cortez, 2003.

PASSETTI, E. Foucault-antifascista, São Francisco de SalesGuia e atitudes de parresiasta. In: RAGO, M.; VEIGA-NETO, A. (Org.). Para uma vida não-fascista. Belo Horizonte: Autêntica, 2009. p. 117-134.

PELBART. P. P. Vida capital: ensaios de biopolítica. São Paulo: Iluminuras, 2009.

SANT'ANNA, D. B. Transformações do corpo: controle de si e uso dos prazeres. In: RAGO, M.; ORLANDI, L. L.; VEIGANETO, A. (Org.). Imagens de Foucault e Deleuze: ressonâncias nietzscheanas. Rio de Janeiro: DP\&A. 2005. p. 99-110.

SANT'ANNA, D. B. Dietética e conhecimento de si. In: RAGO, M.; VEIGA-NETO, A. (Org.). Para uma vida nãofascista. Belo Horizonte: Autêntica, 2009. p. 83-94.

SOARES, C. L. Escultura da carne: o bem-estar e as pedagogias totalitárias do corpo. In: RAGO, M.; VEIGA-NETO, A. (orgs.) Para uma vida não-fascista. Belo Horizonte: Autêntica Editora, 2009. pp. 63-82.

VASCONCELOS, M. F. F. A infâmia de Quincas: (re) existências de corpos em tempos de biopolítica. 2013. Tese (Doutorado)-Faculdade de Educação, Programa de PósGraduação em Educação, Universidade Federal do Rio Grande do Sul, Porto Alegre, 2013.

ZAGO, L. F. Corpo-currículo na cultura somática. In: SEMINÁRIO BRASILEIRO DE ESTUDOS CULTURAIS EM EDUCAÇÃO, 5, 2013, Canoas. Anais... Canoas: ULBRA, 2013a. p. 1-12.

ZAGO, L. F. "Armários de vidro" e "Corpos-sem-cabeça" na biossociabilidade gay online. Interface - comunicação, saúde e educação, [S.1.], v. 17, n. 45, p. 419-432, 2013b.

Recebido em: 2 de abril de 2015 Aceito em: 3 de setembro de 2015 